\title{
The Longitudinal Israeli Study of Twins (LIST): Children's Social Development as Influenced by Genetics, Abilities, and Socialization
}

\author{
Ariel Knafo \\ Department of Psychology, The Hebrew University of Jerusalem, Israel
}

$T^{\text {ne }}$ he goals, prospects and methods of the Longitudinal Israeli Study of Twins (LIST) are described. This study is interested in children's prosocial development from phenotypic, genetic and environmental perspectives. It focuses on measuring prosociality with a multi-trait multi-method approach, and relating it to children's general cognitive and sociocognitive abilities, and to parenting in the family. Other variables of interest such as children's temperament and parental values are discussed, as are ideas for further research.

Developmental processes play an important role in determining the relative importance of genetic and environmental influences on children's prosocial behavior (Knafo \& Plomin, 2006a, 2006b). In a longitudinal study of British twins $(N=9400$ pairs) aged $2,3,4$, and 7 , the heritability of parentrated prosocial behavior increased with age from .32 to .61 , whereas environmental effects shared by twins decreased from .47 at age 2 to .03 at age 7 (Knafo \& Plomin, 2006b). Longitudinal genetic analyses showed that genetics account for both change and continuity in prosocial behavior and that the environment not shared by twins contributes mainly to change (Knafo \& Plomin, $2006 \mathrm{~b})$. We also addressed the role of parenting. Parental positive feelings and discipline correlated positively with prosocial behavior, an effect attributed mainly to the environment shared by family members (Knafo \& Plomin, 2006a). Furthermore, genetic factors were responsible for a substantial part of a negative correlation between parental negativity and prosocial behavior (Knafo \& Plomin, 2006a).

However, these findings raised additional issues that could not be answered by the questionnairebased reports by Knafo and Plomin (2006a, 2006 b). For example, what are the 'new' genetic effects that are responsible for change as children grow up? Could they be traced back to genetic influences on cognitive abilities, temperament, or both (e.g., Russell et al., 2003; Zahn-Waxler et al., 1982)? What is the role of parenting? Does it operate, perhaps contrary to most intuitions, through making children different from their siblings (the nonshared environment, see Asbury et al., 2003; Deater-Deckard et al., 2001)? Finally, although a meta-analysis found that prosocial behavior increased with age during childhood, assessment methods and type of behavior (e.g., sharing vs. help) interacted with age in predicting the extent of prosocial behavior, calling for further research (Eisenberg \& Fabes, 1998). Therefore, a developmental study using age-appropriate assessment methods and different types of prosocial behavior is needed. Especially intriguing is the question of potentially different genetic influences on sharing, caring, and helping. These considerations have led to the establishment of the Longitudinal Israeli Study of Twins (LIST).

At the time of writing, data collection at age 3 had just started (the next wave of data collection is planned for age 4.5 years). Therefore, no findings will be presented here. Instead, the author provides a brief outline of the main questions and methods of LIST.

\section{Genetic Research in Israel}

Molecular genetic research in Israel is very active (see, e.g., Kaufer et al., 1998; Lev-Maor et al., 2003; Tirosh et al., 2006). Several groups are involved in high quality behavior genetics molecular research (e.g., Auerbach et al., 2001; Ebstein \& Belmaker, 1997; Lerer et al., 2003; Shifman et al., 2002; Yirmiya et al., 2006).

Received 25 July, 2006; accepted 31 July, 2006.

Address for correspondence: Ariel Knafo, Department of Psychology, the Hebrew University of Jerusalem, Jerusalem 91905, Israel. E-mail: msarielk@mscc.huji.ac.il 
However, quantitative behavior genetics studies are still lacking. Notable are the pioneering twin studies by Guttman and her colleagues (e.g., Fischbein et al., 1999) which had a special focus on twins in the Kibbutzim, a unique Israeli kind of community. But they are more an exception than the rule (see Reichenberg et al., 2000, for another notable exception). It is hoped that LIST will advance the research basis in Israel, through initiating a quality longitudinal twin sample to be followed in later ages to study social development.

Twinning is becoming increasingly common in Israel, with a $30 \%$ increase in multiple births over the last decade (Israel Central Bureau of Statistics, 2004). This is probably due to a combination of increasingly advanced fertility and neonatology technologies and a high cultural importance given to childbearing. Currently, about $5.1 \%$ of Jewish children in Israel are of multiple births (Israel Central Bureau of Statistics, 2004). This proportion is higher than in other countries with twin registries, such as Australia, Finland, Germany, the Netherlands, Sri Lanka, Sweden, the United Kingdom, and the United States (United Nations Demographic Yearbook, 1999). In Arab families in Israel, the proportion is lower than among Jews (3.5\%; Israel Central Bureau of Statistics, 2004), although this proportion is still very high by international standards. An important implication for genetically-oriented research on twins in Israel is that a high number of twins are born with the help of assisted reproductive technologies, and many of them are born preterm. Through LIST, families will be screened for biases in the age of parents, children's health, and other potential implications, in order to enable valid conclusions to be drawn from comparing monozygotic and dizygotic twin pairs.

\section{Main Research Questions}

The main research questions to be addressed by LIST are:

(1) What are the phenotypic, genetic, and environmental relations among different modalities of prosocial behavior? An important distinction has been made in the scientific literature between two types of prosocial behavior: Compliant prosocial behavior and self-initiated prosocial behavior. Compliant prosocial behavior refers to those behaviors elicited in response to social requirements, whereas self-initiated prosocial behaviors are voluntarily chosen behaviors (Eisenberg et al., 1984; Grusec, 1991). This distinction is relevant to age differences in prosocial behavior (Eisenberg et al., 1992; Zarbatany et al., 1985) and in the motivations behind it (Bar-Tal, 1982), and to the potential effects of parenting (Eisenberg et al., 1992; Grusec, 1991). A question we would like to answer, for example, is: Do individual differences in different kinds of prosocial behavior load on the same genetic factors?

(2) What is the role of age in the development of prosocial behavior? Between ages 3 and 4.5 years, dramatic changes in children's sociocognitive abilities occur (Goetz, 2003; Ritblatt, 2000; Sperling et al., 2000). Could these developments account for the increase in prosociality around this age, as reported by Eisenberg and Fabes (1998)? Age differences in the extent of different aspects of prosocial behavior will be studied, and so will the hypotheses that from age 3 to age 4.5 there will be an increase in heritability and a decrease in the importance of shared environmental effects, and that genetic and environmental factors both contribute to change and stability in prosocial behavior (Knafo \& Plomin, 2006b).

(3) What is the relationship between cognitive abilities and prosocial behavior? In order to behave prosocially, children have to identify others' needs (Pearl, 1985). They have to perceive social cues calling for prosocial behavior, and to know how to provide others with help, resources, or support. Therefore, cognitive abilities are important for prosocial behavior. Indeed, general cognitive abilities correlate with prosocial behavior moderately (e.g., Zahn-Waxler et al., 1982). It is also important to study specific sociocognitive abilities such as cognitive perspective taking (the ability to understand others' intentions and infer others' knowledge). The phenotypic, genetic and environmental relationships between prosocial behavior and cognitive abilities will be studied. For example, we will investigate whether the relationship between the sociocognitive ability of affective perspective taking (knowing others' affective states) and prosocial behavior is due to common genetic factors, common environmental factors, or both.

(4) What is the role of the social context in the development of prosocial behavior? Studies on the relationship between prosociality and socioeconomic status (SES) have yielded mixed results (Burbach et al., 2004; Eisenberg et al., 1993; Hertz-Lazarowitz et al., 1989; Raviv \& Bar-Tal, 1981). We will address this relationship in our study, using a broad set of indicators of prosociality. Another important social context variable is parenting. Warm, supportive parenting may increase prosocial behavior by providing a caring model for children, and by increasing children's willingness to attend to parental messages and their accuracy in detecting these messages (Knafo \& Schwartz, 2003; Staub, 1979). But the effects of parenting, especially of the harsh and negative kind, can partially reflect the child's genetic tendencies (Knafo \& Plomin, 2006a). Using our longitudinal-genetic design we will address the 
genetic and environmental contributions to the relationships between parenting and prosociality.

\section{Study Design and Sample}

There are about 3100 twin births per year in Israel (Israel Central Bureau of Statistics, 2004). The 2004 and 2005 birth cohorts constitute the first tier of the study. The Ministry of the Interior has agreed to provide contact details for twins' families, based on information about mothers giving birth to more than one child within 24 hours. Families are contacted with mail surveys regarding children's temperament and behavior (see Table 1).

Families in the larger Jerusalem area (an area that is very diverse in sociodemographic terms), constitute the second tier of the study. Families in this area were chosen for observational studies and in-person assessments. We limit ourselves to monozygotic and same-sex dizygotic twin pairs as the expense and effort associated with videotaped structured and naturalistic observations put a limit on the sample size for the observational study. In addition to participating in the questionnaire phase of the study, they are contacted by phone by the research team to ask for participation and set a meeting close to the twins' 3rd birthday. In this meeting, experimental measures of prosocial behavior are taken, tests of general and specific cognitive abilities are performed, and mother-child behaviors are videotaped to be coded later. When participants complete all assessments, children receive rewards for participation, and parents are monetarily compensated for their time. A sample size of 500 pairs is sought for this subsample.

We plan to call families again when the twins are 4.5 years old. To maintain contact with families, parents are invited between data collection points to enter the study's website, to browse basic study results and information about twins, parenting and child development. A newsletter about twins is another method used to communicate with families. The possibility of reaching part of the sample (e.g., selected as extreme on one trait for extremes analyses) is also considered.

\section{Measures}

\section{Zygosity questionnaire}

Twins' zygosity is determined using an algorithm based on answers to a parental questionnaire of physical similarity (Goldsmith, 1991). This questionnaire is also used in the Twins' Early Development Study (Plomin et al., 2002). It has been shown to be over $95 \%$ accurate when compared to DNA testing (Price et al., 2000). DNA tests will be used for an estimated $5 \%$ for which questionnaires may not provide definite answers.

\section{Demographic variables}

Mothers and fathers are asked to provide basic information on demographic and health issues (e.g., birthweight for the purpose of screening children with extreme developmental problems). They also report the demographic characteristics of the family regarding SES, religion, family size, and so on. Information about the twins' social settings (e.g., whether they go to preschool or not, and for how long) is also recorded.

\section{Children's behavior}

We assess twins' behavior, especially prosocial behavior, from a multi-trait multi-method perspective, using questionnaires, observation of behavior in a free play session, and experimental measures. All of the questionnaires have been translated into Hebrew and

Table 1

Questionnaire Measures of Children's Development

\begin{tabular}{ll}
\hline Scale & Source \\
\hline Temperament & \\
Activity & EAS Temperament Survey (Buss \& Plomin, 1984) \\
Sociability & EAS \\
Shyness & EAS \\
(Negative) emotionality & EAS \\
Socioemotional traits & \\
Mastery & The Infant-Toddler Social and Emotional Assessment (ITSEA, Carter et al., 2003) \\
Empathy & Kochanska et al., 1994 \\
Prosociality & Strengths and Difficulties Questionnaire (SDQ; Goodman, 1997) \\
Psychological problems & \\
Emotional problems & SD0 \\
Conduct problems & SD0 \\
Hyperactivity & SD0 \\
Peer problems & SD0 \\
\hline
\end{tabular}


back-translated into English to ensure the validity of the translation, and piloted on an independent sample, as is common practice in cross-cultural research. Mothers fill out questionnaires including several scales describing each of the twins, focusing on their temperament, psychological problems, and social development (mastery, empathy and prosociality see Table 1).

The experimental measures of prosocial behavior are introduced during the testing session, when the experimenters present to the child a set of situations which potentially elicit prosocial responses. Selfinitiated (following no direct request) and compliant (following a specific, nonpressuring request by the experimenter) sharing, caring and help are assessed, totaling six measures of prosocial behavior. For example, self-initiated help is assessed when the experimenter 'accidentally' knocks a pencil box on the floor. She says, 'Oops,' continues writing for 20 seconds, and retrieves the pencils for 30 seconds. Children's spontaneous help indicates prosocial behavior (Iannotti, 1985). These measures are mostly adaptations of tasks prevalent in the literature (Denham, 1986; Eisenberg et al., 1987; Radke-Yarrow \& Zahn-Waxler, 1976; Zahn-Waxler et al., 1992).

Mothers and twins (each twin separately) are given play dough sets of many colors, and a set of tools for modeling the dough. They are asked to play freely with the dough. Videotaped sessions are coded for the occurrence of several prosocial behaviors (e.g.,
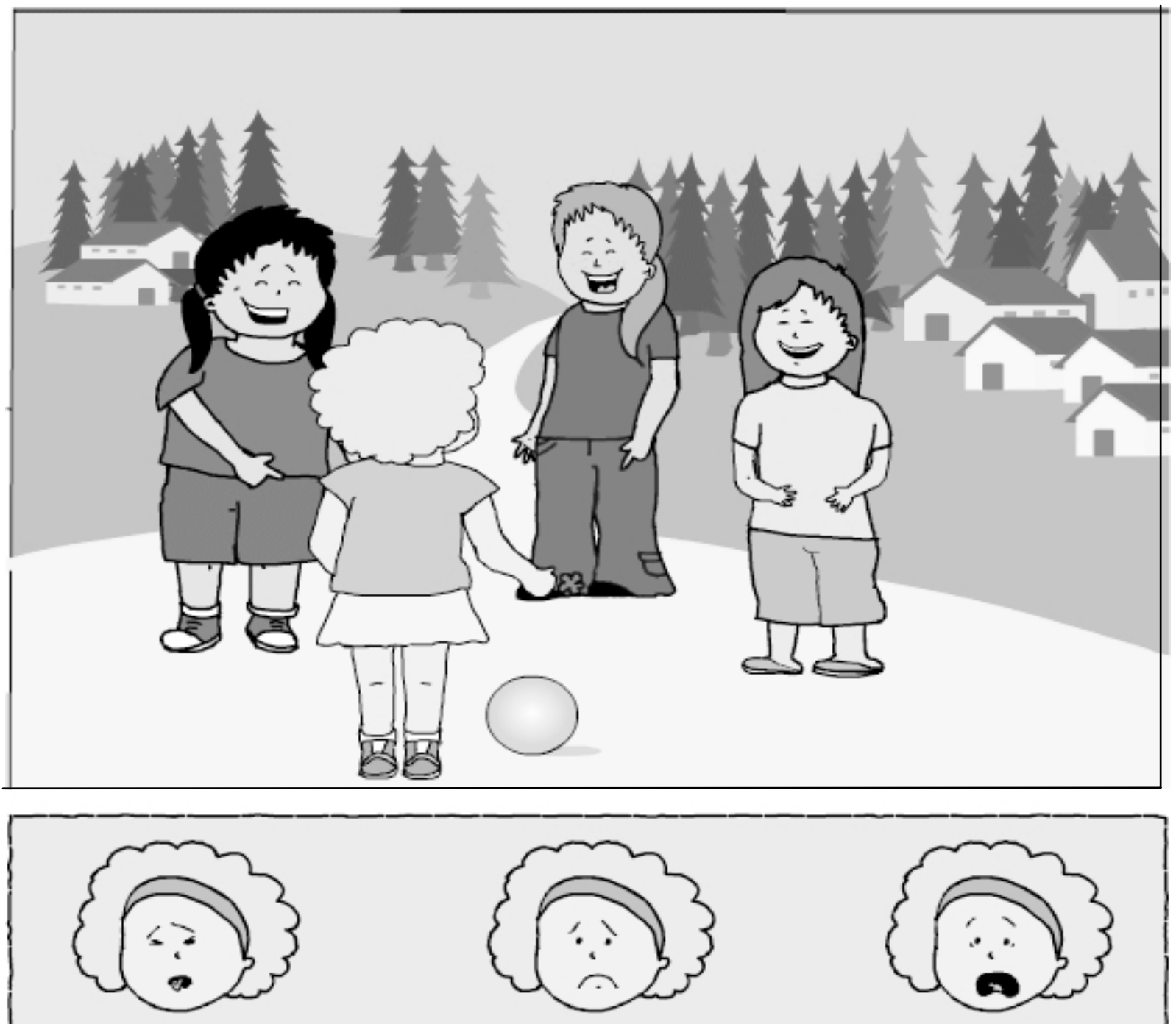

Figure 1

An exemplary item assessing affective perspective taking.

Note: This item is part of an illustrated story that taps several sociocognitive abilities with a single story narrative in which children are asked predetermined questions that assess their abilities. In this example, Kiki is laughed at by friends, a situation eliciting sadness (Ribordy et al., 1988). The child's affective knowledge is assessed both expressively ('How does Kiki feel now?') and receptively ('Can you show me how Kiki looks now?'), a procedure adapted from Denham (1986). Drawing by artist Neta Leshem. 
sharing, helping) that happen as the play develops, based on Marcus (1986).

\section{Parenting}

Because a major interest of this study is in the socialization processes, parents are asked to describe parenting towards each child using the Robinson et al. (1995) scales, assessing warmth, induction and reasoning, autonomy support, corporal punishment, verbal hostility, directiveness, and permissiveness. A recent review, comparing many parenting scales, described this measure as good in terms of breadth, reliability and validity (Locke \& Prinz, 2002). In addition, parents describe their behavior towards each twin using a scale assessing love-withdrawal (adapted from Knafo \& Schwartz, 2003).

Play sessions are also coded for parenting dimensions, such as parental responsiveness (Kochanska, 1997), parental control (Kochanska \& Aksan, 1995), positive and negative affect (Johnston et al., 2002) and parental structure and autonomy-support (Hughes \& Gottlieb, 2004).

\section{General cognitive abilities}

General cognitive abilities are assessed with the mental processing scales of the K-ABC (Kauffman Assessment Battery for Children; Kaufman \& Kaufman, 1983), a relatively culture-free test of abilities such as sequential processing, memory, and simultaneous processing. The Israeli version has been tested and normed with 2000 children aged 3 to 12 years, under the supervision of the Ministry of Education's Psychological Services (Peyser et al., 1996), and used extensively ever since. Suitability for ages 3 to 12 years makes it appropriate for a longitudinal study.

\section{Sociocognitive abilities}

Sociocognitive abilities are assessed with an illustrated story that incorporates several tasks from past studies into a single narrative, presenting children with stimuli in a consistent, engaging and interesting manner. While the experimenter reads the story, she asks the child questions that tap sociocognitive abilities. For example, after story character Kiki (matched to the child's sex) is laughed at by friends, a situation eliciting sadness, the child's affective knowledge is assessed both expressively and receptively (procedure adapted from Denham, 1986): The child is asked how Kiki feels, and is then shown three faces of Kiki expressing different emotions (e.g., sad, angry, disgusted) to choose from (see Figure 1). This is one of five situations adapted from vignettes by Ribordy et al., (1988) to assess affective perspective taking. Five tasks (Wellman \& Wooley, 1990; Yuill et al., 1996) assess desire understanding, presenting children with story characters' focused desires and asking for their behavior following occurrences, such as not finding what they wanted or finding a substitute. Another aspect of cognitive perspective taking includes three false-belief tasks (Harris et al., 1989). For example, children are required to ignore their knowledge of the unexpected contents of a box (the Smarties task) or an object's unexpected location (Sally-Ann task; Wimmer \& Perner, 1983).

\section{Additional Research Questions and Potential for Collaboration}

The data collected in LIST are expected to provide answers for other important developmental questions regarding prosocial behavior and other traits of interest. For example, there is evidence that temperament is related to prosocial behavior (Russell et al., 2003). Our data will enable an investigation of the extent to which genetic factors are responsible for this association. Similarly, parental values are similar to a certain extent to the values of children (Knafo, 2003; Knafo $\&$ Schwartz, 2004). Parental values also predict children's prosocial behavior (Eisenberg et al., 1992). The role of parents' values will be looked at (using the Portrait Values Questionnaire; Knafo \& Schwartz, 2003; Schwartz \& Rubel, 2005), in order to investigate whether these relationships reflect shared environmental influences. Finally, discussions with many parents of twins in Israel show a recurrent theme: Parents of twins are willing to help research, but they want to feel they get something 'in return'. Therefore, a part of our study will focus on twin-specific developmental issues.

The study will lay the foundation for further research at age 6 and older. As data collection continues, it is likely that new research questions will arise. Primarily, we will seek to incorporate a molecular genetic aspect within this study. In addition to identifying DNA markers relevant to prosocial behavior, we hope this will constitute a valuable source of information on the genetic influences on children's behavior in other domains. It will also provide a framework for collaboration with researchers from related fields and from other countries interested in children's personality, social, and cognitive development.

\section{Acknowledgments}

The author thanks Gali Naor and Rivka Shpigelman for their comments on this report. LIST is supported by a grant from the Israel Science Foundation.

\section{References}

Asbury, K., Dunn, J. F., Pike, A., \& Plomin, R. (2003). Nonshared environmental influences on individual differences in early behavioral development: A monozygotic twin differences study. Child Development, 74, 933-943.

Auerbach, J. G., Benjamin, J., Faroy, M., Geller, V., \& Ebstein, R. (2001). DRD4 related to infant attention and information processing: A developmental link to ADHD? Psychiatry Genetics, 11, 31-35.

Bar-Tal, D. (1982). Sequencial development of helping behavior: A cognitive-learning approach. Developmental Review, 2, 101-124. 
Burbach, A. D., Fox, R. A., \& Nicholson, B. C. (2004). Challenging behaviors in young children: The father's role. Journal of Genetic Psychology, 165, 169-183.

Buss, A. H., \& Plomin, R. (1984). Temperament: Early developing personality traits. Hillsdale, NJ: Lawrence Erlbaum.

Carter, A. S., Briggs-Gowan, M. J., Jones, S. M., \& Little, T. D. (2003). The Infant-Toddler Social and Emotional Assessment: Factor structure, reliability, and validity. Journal of Abnormal Child Psychology, 31, 495-514.

Deater-Deckard, K., Dunn, J., O’Connor, T. G., Davies, L., \& Golding, J. (2001). Using the stepfamily genetic design to examine gene-environment processes in child and family functioning. Marriage and Family Review, 33, 131-156

Denham, S. (1986). Social cognition, prosocial behavior and emotion in preschoolers: Contextual validation. Child Development, 57, 194-201.

Ebstein, R. P., \& Belmaker, R. H. (1997). Saga of an adventure gene: Novelty Seeking, substance abuse and the dopamine D4 receptor (D4DR) exon III repeat polymorphism. Molecular Psychiatry, 2, 381-384.

Eisenberg, N., Cameron, E., \& Tryon, F. (1984). Prosocial behavior in the preschool years: Methodological and conceptual issues. In E. Staub, D. Bar-Tal, J. Karylowski, \& J. Reykowski (Eds.), The development and maintenance of prosocial behavior: International perspectives on positive development (pp. 101-115). New York: Plenum.

Eisenberg, N., \& Fabes, R. A. (1998). Prosocial development. In N. Eisenberg \& W. Damon (Eds.), Handbook of child development: Vol. 4. Social, emotional and personality development (5th ed., pp. 701-778). New York: John Wiley \& Sons Inc.

Eisenberg, N., Fabes, R. A., Carlo, G., Speer, A. L., Switzer, G., Karbon, M., \& Troyer, D. (1993). The relations of empathy-related emotions and maternal practices to children's comforting behavior. Journal of Experimental Child Psychology, 55, 131-150.

Eisenberg, N., Shell, R., Pasternak, J., Lennon, R., Beller, R., \& Mathy, R. (1987). Prosocial development in middle childhood: A longitudinal study. Developmental Psychology, 23, 712-718.

Eisenberg, N., Wolchik, S. A., \& Goldberg, L. (1992). Parental values, reinforcement, and young children's prosocial behavior: A longitudinal study. Journal of Genetic Psychology, 153, 19-36.

Fischbein, S., Guttman, R., \& Nathan, M. (1999). Genetic and environmental influences on pupil performances. Twin Research, 2, 183-195.

Goetz, P. J. (2003). The effects of bilingualism on theory of mind development. Bilingualism: Language and Cognition, 6, 1-15.
Goldsmith, H. H. (1991). A zygosity questionnaire for young twins: A research note. Behavior Genetics, 21, 257-269.

Grusec, J. E. (1991). Socializing concern for others in the home. Developmental Psychology, 27, 338-342.

Goodman, R. (1997). The Strengths and Difficulties Questionnaire: A research note. Journal of Child Psychology and Psychiatry, 38, 581-586.

Harris, P. L., Johnson, C., N., Hutton, D., Andrews, G., \& Cooke, T. (1989). Young children's theory of mind and emotion. Cognition and Emotion, 3, 379-400.

HertzLazarowitz, R., Fuchs, I., Sharabany, R., \& Eisenberg, N. (1989). Students' interactive and noninteractive behaviors in the classroom: A comparison between two types of classroom in the city and the kibbutz in Israel. Contemporary Educational Psychology, 14, 2232.

Hughes, J. R., \& Gottlieb, L. N., (2004). The effects of the Webster-Stratton parenting program on maltreating families: Fostering strengths. Child Abuse and Neglect, 28, 1081-1097.

Iannotti, R. J. (1985). Naturalistic and structured assessments of prosocial behavior in preschool children: The influence of empathy and perspective taking. Developmental Psychology, 21, 46-55.

Israel Central Bureau of Statistics (2004). Fertility patterns in Israel in 2003. Retrieved on September 10, 2004, from www.cbs.gov.il/hodaot2004/01_04_ 230.htm (Hebrew).

Johnston, C., Murray, C., Hinshaw, S. P., Pelham, W. E., \& Hoza, B. (2002). Responsiveness in interactions of mothers and sons with ADHD: Relationships to maternal and child characteristics. Journal of Abnormal Child Psychology, 30, 77-88.

Kaufer, D., Friedman, A., Seidman, S., \& Soreq, H. (1998). Acute stress facilitates long-lasting changes in cholinergic gene expression. Nature, 393, 373-377.

Kaufman, A. S., \& Kaufman, N. L. (1983). Kaufman assessment battery for children (K-ABC). Minneapolis: American Guidance Services.

Knafo, A. (2003). Contexts, relationship quality, and family value socialization: The case of parent-school ideological fit in Israel. Personal Relationships, 10, 373-390.

Knafo, A., \& Plomin, R. (2006a). Parental discipline and affection, and children's prosocial behavior: Genetic and environmental links. Journal of Personality and Social Psychology, 90, 147-164.

Knafo, A., \& Plomin, R. (2006b). Prosocial behavior from early to middle childhood: Genetic and environmental influences on stability and change. Developmental Psychology, 42, 771-786.

Knafo, A., \& Schwartz, S. H. (2003). Parenting and accuracy of perception of parental values by adolescents. Child Development, 73, 595-611. 
Knafo, A., \& Schwartz, S. H. (2004). Identity status and parent-child value congruence in adolescence. British Journal of Developmental Psychology, 22, 439-458.

Kochanska, G. (1997). Mutually responsive orientation between mothers and their young children: Implications for early socialization. Child Development, 68, 94-112.

Kochanska, G., \& Aksan, N. (1995). Mother-child mutually positive affect, the quality of child compliance to requests and prohibitions, and maternal control as correlates of early internalization. Child Development, 66, 236-254.

Kochanska, G., DeVet, K., Goldman, M., Murray, K., \& Putnam, S. (1994). Maternal reports of conscience development and temperament in young children. Child Development, 65, 852-868.

Lerer, B., Segman, R. H., Hamdan, A., Kanyas, K., Karni, O., Kohn, Y., Korner, M., Lanktree, M., Kaadan, M., Turetsky, N., Yakir, A., Kerem, B., \& Macciardi, F. (2003). Genome scan of Arab Israeli families maps a schizophrenia susceptibility gene to chromosome 6q23 and supports a locus at chromosome 10q24. Molecular Psychiatry, 8, 488-498.

Lev-Maor, G., Sorek, R., Shomron, N., \& Ast, G. (2003). The Birth of an Alternatively Spliced Exon: 3' Splice-Site Selection in Alu Exons. Science, 300, 1288-1291.

Locke, L. M., \& Prinz, R. J. (2002). Measurement of parental discipline and nurturance. Clinical Psychology Review, 22, 895-929.

Marcus, R. F. (1986). Naturalistic observation of cooperation, helping and sharing, and their associations with empathy and affect. In C. Zahn-Waxler, E. M. Cummings, \& R. J. Iannotti (Eds.), Altruism and aggression: Social and biological origins. Cambridge, MA: Cambridge University Press.

Pearl, R. (1985). Children's understanding of others' need for help: Effects of problem explicitness and type. Child Development, 56, 735-745.

Peyser, M., Shimborsky, G., Wolf, N., \& Hazany, I. (1996). K-ABC, Kaufman Assessment Battery for Children: Interpretive manual. Jerusalem: Israel Ministry of Education and the Szold Institute (Hebrew).

Plomin R., Price, T. S., Eley, T. C., Dale, P. S., \& Stevenson, J. (2002). Associations between behaviour problems and verbal and nonverbal cognitive abilities and disabilities in early childhood. Journal of Child Psychology and Psychiatry, 43, 619-633.

Price, T. S., Freeman, B., Craig, I. W., Petrill, S. A., Ebersole, L., \& Plomin, R. (2000). Infant zygosity can be assigned by parental report questionnaire data. Twin Research, 3, 129-133.

Radke-Yarrow, M., \& Zahn-Waxler, C. (1976). Dimensions and correlates of prosocial behavior in young children. Child Development, 47, 118-125.
Raviv, A., \& Bar-Tal, D. (1981). Demographic correlates of adolescents' helping behavior. Journal of Youth and Adolescence, 10, 45-54.

Reichenberg, A., Rabinowitz, J., Weiser, M., Mark, M., Kaplan, Z., \& Davidson, M. (2000). Premorbid functioning in a national population of male twins discordant for psychoses. American Journal of Psychiatry, 157, 1514-1516.

Ribordy, S. C., Camras, L. A., Stefani, R., \& Spaccarelli, S. (1988). Vignettes for emotion recognition research and affective therapy with children. Journal of Clinical Child Psychology, 17, 322-325.

Ritblatt, S. N. (2000). Children's level of participation in a false-belief task, age, and theory of mind. Journal of Genetic Psychology, 161, 53-64.

Robinson, C. C., Mandleco, B., Olsen, S. F., \& Hart, C. H. (1995). Authoritative, authoritarian, and permissive parenting practices: Development of a new measure. Psychological Reports, 77, 819-830.

Russell, A., Hart, C. H., Robinson, C., \& Olsen, S. F. (2003). Children's sociable and aggressive behavior with peers: A comparison of the U.S. and Australia, and contributions of temperament and parenting styles. International Journal of Behavioral Development, 27, 74-86.

Schwartz, S. H., \& Rubel, T. (2005). Sex differences in value priorities: Cross-cultural and multi-method studies. Journal of Personality and Social Psychology, 89, 1010-1028.

Shifman, S., Bronstein, M., Sternfeld, M., PisantéShalom, A., Lev-Lehman, E., Weizman, A., Reznik, I., Spivak, B., Grisaru, N., Karp, L., Schiffer, R., Kotler, M., Strous, R. D., Swartz-Vanetik, M., Knobler, H. Y., Shinar, E., Beckmann, J. S., Yakir, B., Risch, N., Zak, N. B., \&, Darvasi., A. (2002). A highly significant association between a COMT haplotype and schizophrenia. American Journal of Human Genetics, 71, 1296-1302.

Sperling, R. A., Walls, R. T., \& Hill, L. A. (2000). Early relationships among self-regulatory constructs: Theory of mind and preschool children's problem solving. Child Study Journal, 30, 233-252.

Staub, E. (1979). Positive social behavior and morality: Socialization and development (Vol. 2). New York: Academic Press.

Tirosh, I., Weinberger, A., Carmi, M., \& Barkai, N. (2006). A genetic signature of interspecies variations in gene expression. Nature Genetics, 38, 830-834.

United Nations Demographic Yearbook (1999). Live births by plurality: 1990-1998. Retrieved on July 20, 2006, from http://unstats.un.org/unsd/demographic/ products/dyb/DYBNat/NatStatTab10.pdf

Wellman, H. M., \& Woolley, J. D. (1990). From simple desires to ordinary beliefs: The early development of everyday psychology. Cognition, 35, 245-275.

Wimmer, H., \& Perner, J. (1983). Beliefs about beliefs: Representation and constraining function of wrong 
beliefs in young children's understanding of deception. Cognition, 13, 103-128.

Yirmiya, N., Rosenberg, C., Levi, S., Salomon, S., Shulman, C., Nemanov, L., Dina, C., \& Ebstein, R. P. (2006). Association between the arginine vasopressin 1a receptor (AVPR1a) gene and autism in a family-based study: Mediation by socialization skills. Molecular Psychiatry, 11, 488-494.

Yuill, N., Perner, J., Pearson, A., Peerbhoy, D., \& VanDen Emde, J. (1996). Children's changing understanding of wicked desires: From objective to subjective and moral. British Journal of Developmental Psychology, 14, 457-475.
Zahn-Waxler, C., Iannotti, R., \& Chapman, M. (1982). Peers and prosocial development. In K. Rubin \& H. Ross (Eds.), Peer relationships and social skills in childhood (pp. 133-162). New York: SpringerVerlag.

Zahn-Waxler, C., Radke-Yarrow, M., Wagner, E., \& Chapman, M. (1992). Development of concern for others. Developmental Psychology, 28, 126-136.

Zarbatany, L., Hartmann, D. P., \& Gelfand, D. M. (1985). Why does children's generosity increase with age: Susceptibility to experimenter influence or altruism? Child Development, 56, 746-756. 